\title{
Development of the Automated Information System for Monitoring of Results of Accounting Object Activities Using Semantic Networks
}

\author{
Valeriya $V$. Tishkina ${ }^{1,}$, Alexander N. Pylkin ${ }^{1}$, Alexander $V$. Kroshilin $^{1}$, and Svetlana $V$. Kroshilina $^{1}$ \\ ${ }^{1}$ Ryazan State Radio Engineering University, 390005 Ryazan, Russia
}

\begin{abstract}
Currently, any management object is characterized by a large amount of information. This information is contained in various documents: in the financial statements, regulations, laws, etc. For information on management object must be converted to a certain type, since the information in the future will need to be analyzed. Knowledge about management object allows making effective and informed decisions. So now the task of not only the collection and storage of information, but also to the transformation of information suitable for the analysis of the user view. Thus, the article focuses on the process of developing a system that allows you to analyze the data about management object and based on the analysis to conclude about the state of the object.
\end{abstract}

\section{Introduction}

At the present time, factors such as the globalization of trade, market uncertainty and fierce competition involve a decrease in profit in the enterprise. There is a need to reduce the probability of erroneous decisions in enterprise management. Two key aspects to achieving this goal are the vitality and competitiveness of enterprises, which is largely dependent upon the effectiveness of decision-making related to the activities of the enterprise. For this reason, the companies took on the task of developing more effective management information systems in order to help decision-makers exploit the data and models that enrich and improve the decision-making process.

The developed system should be improved in order to deal with the large number of available data and heterogeneity of the existing approaches to modeling.

Most of the data arising from the activities of the enterprise, it is in the form of electronic and paper documents. All aspects of economic activity are either document, or can be formally reduced to the document. Today is dominated by relational database management systems that provide a convenient way to store information in the form of tables.

The relational model is sufficient for modeling the subject areas, but the very design of database in terms of the relationship is often very difficult. The need for designers in more convenient and powerful means of presenting the subject area has caused the emergence of semantic modeling.

\section{Intelligent methods in automated analysis of activity of objects of management}

The advantage of automated systems for analysis is the ability to discover hidden knowledge in large volumes of data. Need exists for the use of artificial intelligence methods in systems for analysis of the activity of management objects.

Computational intelligence methods in recent decades have received the development and implementation of activities in the analysis of management objects. These methods include artificial neural networks, genetic algorithms and fuzzy systems [1]. The use of fuzzy sets is popular with enterprise management. Financial indicators characterize certain aspects of the current financial situation of the company. These indicators are business activity, the turnover, profitability, solvency, financial stability, etc. For some indicators are known standard values.

One of the areas of research in the field of artificial intelligence is the problem of knowledge representation. This line solves the problem of knowledge representation in expert systems. Knowledge should have the following features: internal interpretability, structured, connectivity.

The basic models of knowledge representation in expert systems are: production model, frame model, a neural network, the logical model, a semantic network.

After analyzing the advantages and disadvantages of existing models of knowledge representation, we can conclude that the most appropriate model for the 
monitoring of the results of activities of the management object is a model based on semantic networks. Semantic network is a model of knowledge representation, which is based on graph-oriented network structure. Any subject area can be represented by objects and links between them. Semantic network provides domain objects (nodes) and relations between them (the arcs). Models of knowledge based on semantic networks have a number of advantages: the ability to transform into other knowledge representation models; a visual representation of the causal relationships between objects; presentation of data about real objects and relations between them [2].

Figure 1 shows a model of a semantic network for represent of object of management. G1, G2, G3 different types of analysis (marketable assets, current liquidity, absolute liquidity). Relationship (U13, U14 and U15) between objects made using different degrees of dependency. Status of control object is evaluated based on the degree of relatedness of objects. You can make individual conclusions for each management object.

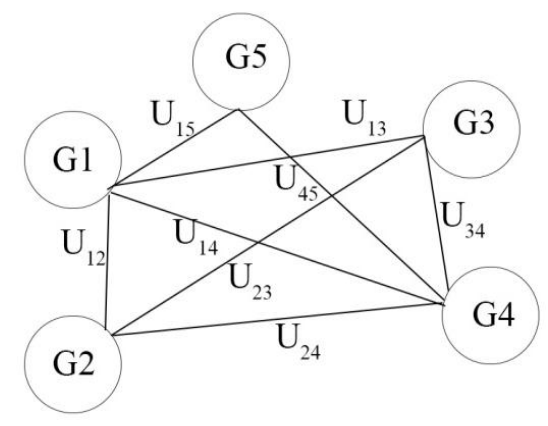

Fig. 1. Model of a semantic network

\section{Development of a system for monitoring the results of activity of accounting objects}

Develop software and information system allows you to analyze the state of the control object on the basis of information about it. An object of management can be analyzed with the help of different types of analysis: financial stability, business activity, profitability, liquidity, management efficiency.

The basis of the developed system is fuzzy logic methods. These financial ratios are analyzed using fuzzy sets theory. A number of parameters of the enterprise is not available to accurately measure.

The developed software system has the following features:

- The possibility of adding new data;

- Entering accounting data;

- Downloading data from the financial statements Excel;

- Monitoring of various parameters of the management object: assessment of business activity, financial stability, management efficiency, liquidity and solvency; - Reporting on the data of different types of analysis of object of management;

- Analysis of the financial ratios using the theory of fuzzy sets.

In the future we plan to develop for software:

- Choice of the kind and branch of object of management;

- The addition of new analysis methods;

- The addition of new metrics analysis;

- The conclusion and recommendations of the analysis of the situation, depending on the type of industry and enterprise.

The fundamental difference from the existing systems of this type is integration. The intuitive interface of the system makes it easy to train staff to operate the system. The developed system saves staff time. Financial analysis system allows drawing conclusions about the real situation on the management object.

\section{References}

1. M. Moharrampour, M. Moharrami, A. Akson, Journal of current research in science, 2 (2014)

2. Hilovska K., Koncz P, Acta VSFS, 6 (2012) 